Research Article

\title{
Seismic Behavior Experimental Study on the Joint of Circular Tubed Steel-Reinforced Concrete Columns
}

\author{
Yan Dai $\mathbb{D}^{1},{ }^{1}$ Shaofeng Nie, ${ }^{2}$ Tianhua Zhou, ${ }^{2}$ Chengfeng Xue, ${ }^{1}$ and Jingrong Peng ${ }^{1}$ \\ ${ }^{1}$ Shaanxi Key Laboratory of Safety and Durability of Concrete Structures, Xijing University, Xi'an 710123, China \\ ${ }^{2}$ School of Civil Engineering, Chang'an University, Xi'an 710061, China \\ Correspondence should be addressed to Yan Dai; daiyan@xijing.edu.cn
}

Received 29 July 2021; Revised 24 August 2021; Accepted 11 September 2021; Published 29 September 2021

Academic Editor: Kang Shao-Bo

Copyright ( 2021 Yan Dai et al. This is an open access article distributed under the Creative Commons Attribution License, which permits unrestricted use, distribution, and reproduction in any medium, provided the original work is properly cited.

A new type joint of Circular Tubed Steel-Reinforced Concrete (CTSRC) columns was designed in this paper. The structural characteristics, manufacturing process, and mechanical properties of raw materials of the new joint were introduced. In order to simulate the earthquake action, two joint specimens were subjected to low-cycle cyclic loading at the end of the column. Based on the in-depth study of the failure characteristics, load-displacement hysteretic curve, skeleton curve, ductility index, load-strain hysteretic curve in the core area of the joint, energy dissipation performance, strength and stiffness degradation performance, and shear deformation in the core area of the joint during the whole loading process, the seismic behavior of this new type of joint was investigated. The results show that the new joint has reasonable failure characteristics, high bearing capacity, good ductility, excellent seismic energy dissipation performance, and strong resistance to strength and stiffness degradation, which meets the seismic design principle of "strong joint and weak component" and is suitable for the results with special requirements for seismic performance. In addition, preliminary design recommendations were put forward. The research results of this paper can provide a theoretical basis for the application of this kind of new structure.

\section{Introduction}

At present, steel-concrete composite structure has been widely used in the field of civil engineering construction. Concrete-filled steel tubular column and steel-reinforced concrete column are two main forms of steel-concrete composite structure. The concrete-filled steel tubular column makes the concrete in the tube in a three-dimensional compressive stress state through the circumferential restraint effect of the outer steel tube on the concrete in the tube, so as to improve the concrete strength and the bearing capacity of the structural column [1-3]. Steel-reinforced concrete column refers to the column concrete, equipped with steel, and with a certain stress and structural reinforcement, steel-reinforced concrete column through the synergistic effect of steel and concrete gives full play to the performance of the two materials and at the same time has excellent seismic performance and good economy. At present, it is widely used in high-rise and superhigh-rise buildings [4].
But the shortcomings of the two are also very obvious. The axial load shared by the steel tube and concrete is easy to cause the buckling of steel tube plate, leading to the decline of seismic performance of columns. Steel-reinforced concrete column is not convenient for concrete pouring because of setting steel skeleton and section steel at the same time, and the steel skeleton has insufficient constraints on concrete, which leads to low axial compression ratio limit and cannot make full use of material properties.

Therefore, on the basis of long-term engineering practice, experience accumulation, and previous research results, a new type of composite structure column has emerged: Circular Tubed Steel-Reinforced Concrete (CTSRC) column. Its outer steel tube is disconnected at the beam-column joint and does not pass through the core area of the joint. Therefore, its steel tube does not directly bear the longitudinal load but only restrains the core concrete, as shown in Figure 1. Research by relevant scholars shows that [5-7] the CTSRC column has high compression and shear bearing 


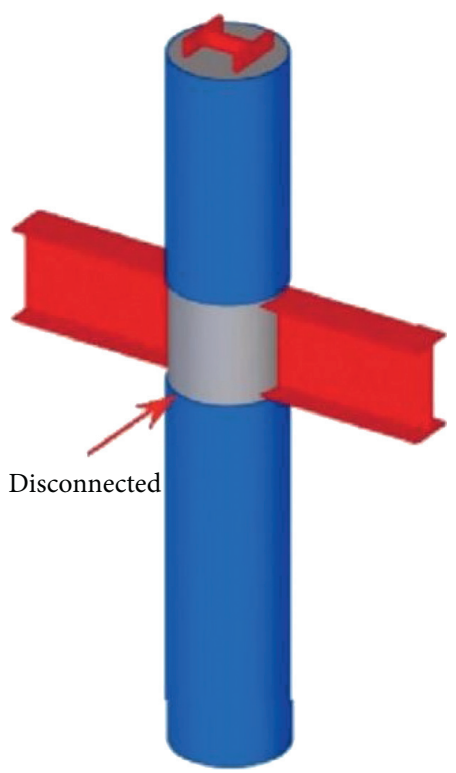

(a)

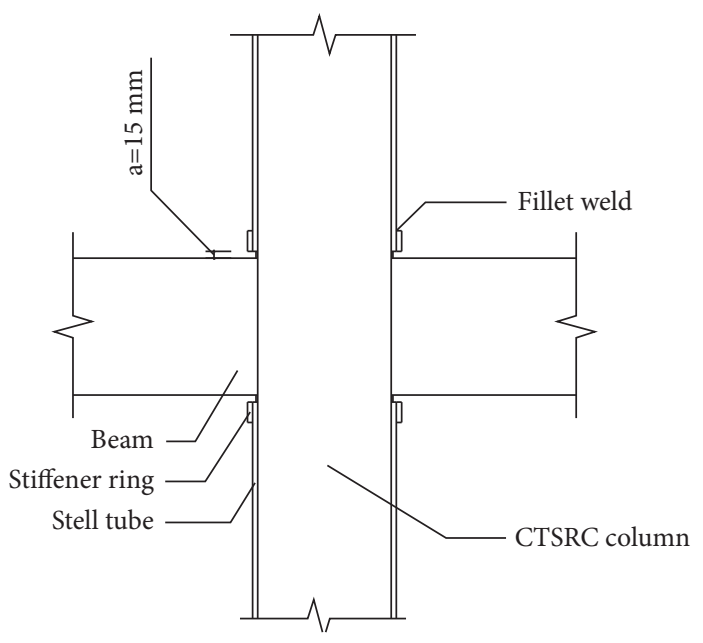

(b)

FiguRe 1: Structural diagram of the circular steel tube-confined H-SRC column steel beam joint. (a) Diagram. (b) Slotted structure of the steel pipe at the column end.

capacity, superior seismic performance, strong interlayer deformation capacity, good fire resistance, and convenient construction and can make full use of high-strength material performance.

In recent years, people have carried out extensive research on the mechanical properties of this structure. Takamasa Yamamoto made three kinds of square and circular steel tube-confined concrete short columns with different cross-section sizes and carried out an axial compression test to study the restraint effect of circular steel tube and square steel tube on concrete [8]. Fam made five specimens to compare the axial bearing capacity of concrete-filled steel tubular columns and confined concrete-filled steel tubular columns. The results show that the axial bearing capacity of confined concrete-filled steel tubular columns is significantly higher [9]. Chen et al. carried out axial compression, eccentric compression, and seismic performance tests on two kinds of partially through CFST column RC beam joints with different strengthening methods [10-12]. Nie et al. studied the axial compression and seismic behavior of a kind of steel tube-confined concrete column RC beam joint with transverse multiple hoops. The results show that this kind of strengthening form can make up for the deficiency caused by the disconnection of steel tube $[13,14]$. Han et al. conducted a comparative experimental study on the hysteretic behavior of steel tubular confined concrete column RC beam joints and steel tubular concrete column RC ring beam joints. The results show that the seismic performance of steel tubular confined concrete column RC beam joints is better than that of steel tubular concrete column RC ring beam joints [15]. Zhang et al. have carried out an experimental study on the seismic behavior of a kind of connection form of concrete-filled steel tubular column and RC beam outer steel tubular unconnected ring beam joint [16]. Gan et al. designed a ring reinforced steel tube-confined RC column joint and studied its axial compression and hysteretic behavior [17]. On the basis of collecting the shear failure results of steel tube-confined reinforced concrete columns with various sections, Gan et al. compared and verified the existing calculation methods and formulas of shear capacity, improved the existing calculation methods, and proposed the calculation formulas of shear capacity for square steel tubes and circular steel tubes, respectively [18]. Duan et al. designed a new type of square steel tubeconfined concrete column joint, carried out two-stage tests to investigate the overall axial compressive behavior of the specimen and the influence of joint geometry size, concrete strength, and mesh volume on its bearing capacity, and proposed the bearing capacity expression of this new type of joint [19]. Lin et al. analyzed the shear mechanism and shear capacity of framework joints of steel-reinforced concrete-filled circular steel tube (SRCFCST), and the calculation method of composite shear capacity in the core area of joints is proposed, which can provide a reference for nonlinear analysis and engineering design of similar joints [20]. Yu et al. designed a new type of joint, in which the concrete in the core area is restrained by the steel tube in the core area, and the outer part is restrained by the ring stirrup. The nonlinear finite element analysis of the axial compression bearing capacity test was carried out, the influence of the steel tube and stirrup in the core area on the bearing capacity is discussed, and the calculation formula of the ultimate bearing capacity is proposed [21-23]. Peng et al. designed four specimens of concrete-filled square steel tubular frame joints with unequal beam heights, carried out low-cycle cyclic loading tests, discussed their seismic performance, and analyzed their shear capacity [24]. 
Literature review shows that the mechanical properties of the CTSRC column are superior, and it has a wide application prospect, but there are two main deficiencies in its research.

Firstly, at present, the research of CTSRC structures mainly focuses on the axial compression performance of columns and joints, and the research on seismic performance of joints is less. If the joints are damaged, the whole structure will be destroyed no matter how strong the beamcolumn members are. Therefore, it is necessary to study the seismic performance on joints of the CTSRC column.

Secondly, the existing research on seismic performance on joints of CTSRC column is carried out by a small-scale model. There is a big difference between the test and the actual situation, and the representativeness is not strong.

As a consequence, it is necessary to study the seismic performance on joints of the CTSRC column, especially the way to strengthen the weakened joint area, the impact of the strengthened joint area on the seismic performance of such joints, and the way to make it meet the design principles of strong column, weak beam, and stronger joint. It is the key problem to be solved in steel tube-confined steel-reinforced concrete structure. Therefore, a new type joint is designed in this paper. The concrete ring beam is used to strengthen the weakened joint area, as shown in Figure 2. The specimen is designed with the size of $1: 1$. Through the pseudostatic test method, the displacement and strain data of each part of the specimen are collected, and the seismic mechanical properties are further studied. It provides a theoretical basis for the popularization and application of this kind of new structure.

\section{Test Plan}

2.1. Specimen Design and Manufacturing. In this paper, two full-scale frame joints are designed, the height is $4375 \mathrm{~mm}$, the outer diameter of the cylinder is $400 \mathrm{~mm}$, the wall thickness of the circular steel tube is $5 \mathrm{~mm}$, and the width is $3370 \mathrm{~mm}$. In order to ensure that the circular steel tube does not bear the longitudinal load, the circular steel tube is disconnected in the joint area, and a $15 \mathrm{~mm}$ ring opening is reserved from the upper and lower edges of the concrete ring beam. The other structures and dimensions are shown in Figure 3 (taking $\mathrm{SH}-1$ specimen as an example), and the parameters of the specimen are shown in Table 1.

In this paper, the specimen processing is divided into four stages: first, steel structure processing and component assembly; second, sticking strain gauges; third, formwork and concrete pouring; finally, curing and specimen painting antirust.

2.2. Mechanical Properties of Materials. The measured average cube compressive strength of the test reserved concrete block is $57.58 \mathrm{MPa}$, and the material properties of steel and reinforcement are shown in Table 2.

2.3. Test Device. The joint specimen is loaded by reaction wall and reaction frame. The horizontal loading device adopts MTS electrohydraulic servo program-controlled structure testing machine. The maximum load of the actuator applying horizontal reciprocating load is $500 \mathrm{kN}$, and the travel range is $\pm 250 \mathrm{~mm}$. The maximum load of the jack used in the vertical loading test is $2000 \mathrm{kN}$. The loading schematic diagram and loading panoramic photo are shown in Figures 4 and 5.

2.4. Loading System. There are two loading methods for seismic performance test of joints: one is beam end loading and the other is column end loading. Because the column end loading can simulate the second-order gravity effect ( $\mathrm{P}-\Delta$ effect) of buildings under earthquake, the column end loading method is adopted in this paper, as shown in Figure 4, and the beam end is supported by a chain bar. The vertical displacement, rotation angle, and horizontal displacement can be realized at the top of the column. This loading method can truly reflect the deformation and mechanical performance of beam-column joints under earthquake.

On the basis of referring to relevant specifications [25] and relevant research $[26,27]$, the specific loading system is determined. Displacement loading mode is adopted in the whole loading process of column top. First, apply the axial load on the column top, and then apply the horizontal load, which is loaded to the yield displacement by 2-3 single cycles. After yielding, the load is carried out according to the multiple of the yield displacement value of the column top. Each cycle is repeated three times (as shown in Figure 6). The cycle does not stop until the specimen is damaged or the horizontal load of the column top drops below $85 \%$ of its peak load $[16,25]$. In the loading system, the yield displacement of the column top of the joint specimen is the estimated value of the horizontal displacement of the column top when the stress of the flange edge of the section at the junction of the steel beam and the concrete ring beam reaches " $f_{y}$." In the test, the loading steps are determined or adjusted in combination with the relevant instrument values. At the same time, the yield point of the specimen is judged from the change of the load-displacement hysteretic curve, and the hysteretic curve is analyzed after the test. The actual yield point of the specimen is determined [25-27].

2.5. Measuring the Content. The test includes displacement measurement and strain measurement. The deformation of the specimen is measured by displacement meter and dial indicator, the strain of circular steel tube, section steel in column, steel beam, and concrete ring beam, reinforcement is measured by strain gauge or strain rosette, the data measured by strain gauge is collected by TDS-602 static strain measurement system and input into a computer, the load-displacement hysteretic curve of column top is automatically collected by MTS servo actuator, and the concrete cracks are measured by crack observation instrument.

\section{Test Results}

3.1. Analysis of Failure Characteristics of Specimens. Because the design parameters of the two specimens are basically similar, the failure modes of the two specimens are 


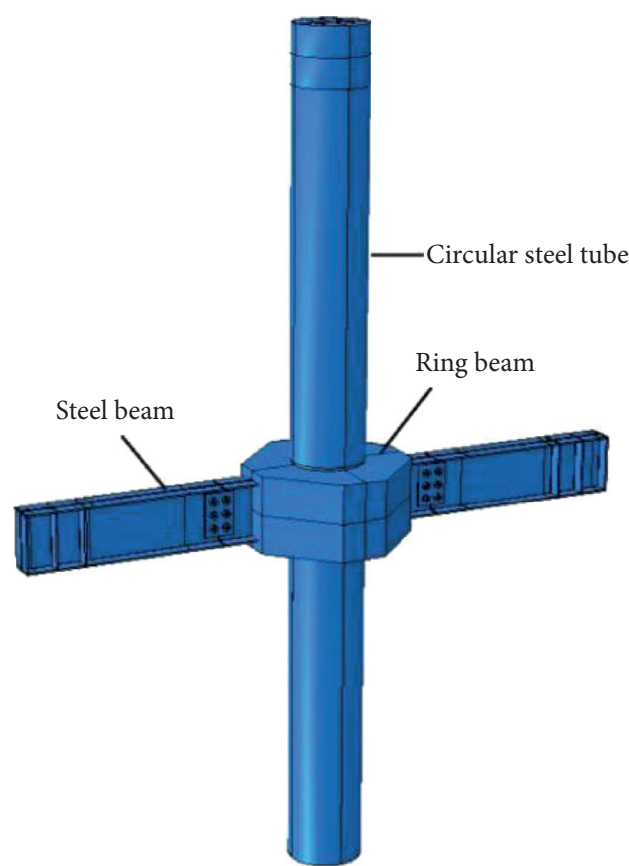

(a)

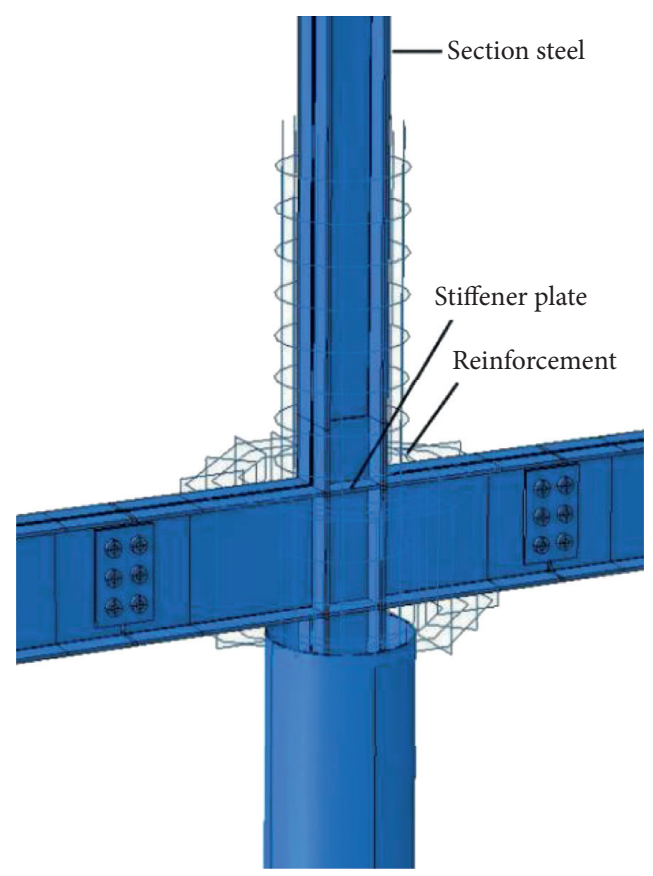

(b)

Figure 2: Schematic diagram of the specimen structure. (a) Overall structure of the specimen. (b) Internal structure of the joint area.

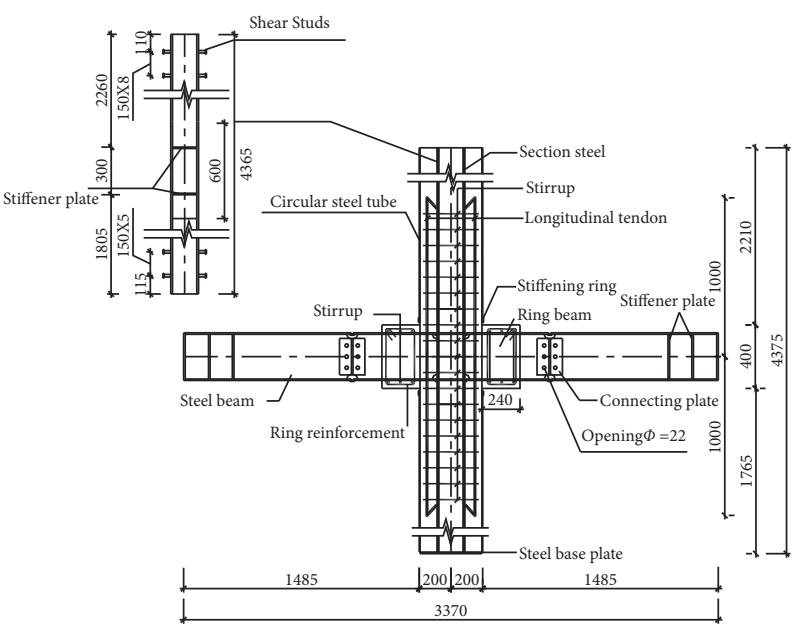

(a)

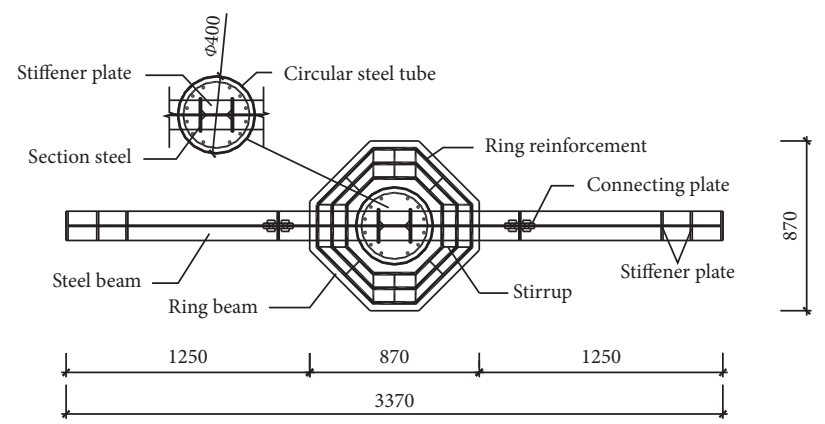

(b)

Figure 3: Structural diagram of specimen (SH-1). (a) Elevation (mm). (b) Plan (mm).

TABle 1: Parameters of the specimen.

\begin{tabular}{lcccc}
\hline $\begin{array}{l}\text { Specimen } \\
\text { number }\end{array}$ & $\begin{array}{c}\text { Steel ratio } \\
(\%)\end{array}$ & $\begin{array}{c}\text { Thickness of the circular tube steel pipe } \\
(\mathrm{mm})\end{array}$ & $\begin{array}{c}\text { Form of the ring } \\
\text { beam }\end{array}$ & $\begin{array}{c}\text { Reinforcement ratio of the ring beam } \\
(\%)\end{array}$ \\
\hline SH-1 & 4.19 & 5 & Octagon & 3.55 \\
SH-2 & & \multirow{2}{*}{ circular } & 2.05 \\
\hline
\end{tabular}

obviously similar, the failure starts from the concrete cracking at the junction of the steel beam and the ring beam, and with the continuous increase of the horizontal displacement at the top of the column, the flange at the junction of the steel beam and the ring beam first enters into yield.
Finally, the two specimens are in full section shape at the end of the steel beam about $5 \mathrm{~cm}$ away from the edge of the ring beam. Plastic hinge is formed (because of the quality problem of the lower flange weld of the steel beam on the west side of the $\mathrm{SH}-1$ specimen, the lower flange of the steel 
TABLE 2: Steel material data.

\begin{tabular}{lcccc}
\hline $\begin{array}{l}\text { Location of the material test } \\
\text { piece }\end{array}$ & $\begin{array}{c}\text { Yield strength }\left(f_{y}\right) \\
(\mathrm{MPa})\end{array}$ & $\begin{array}{c}\text { Ultimate strength }\left(f_{u}\right) \\
(\mathrm{MPa})\end{array}$ & $\begin{array}{c}\text { Elastic modulus }(E) \\
(\mathrm{MPa})\end{array}$ & $\begin{array}{c}\text { Elongation after fracture } \\
(\%)\end{array}$ \\
\hline Flange (section steel in column) & 284.19 & 437.38 & 212404 & 37.2 \\
Web (section steel in column) & 309.35 & 453.02 & 217199 & 30.0 \\
Flange (steel beam) & 308.26 & 463.54 & 212867 & 23.9 \\
Web (steel beam) & 337.52 & 483.25 & 213321 & 27.7 \\
Circular steel tube & 355.62 & 488.81 & 194907 & 27.2 \\
Reinforcement $(20 \mathrm{~mm})$ & 486.85 & 691.60 & 195426 & 20.2 \\
Reinforcement $(10 \mathrm{~mm})$ & 389.39 & 553.28 & 210564 & 23.0 \\
\hline
\end{tabular}
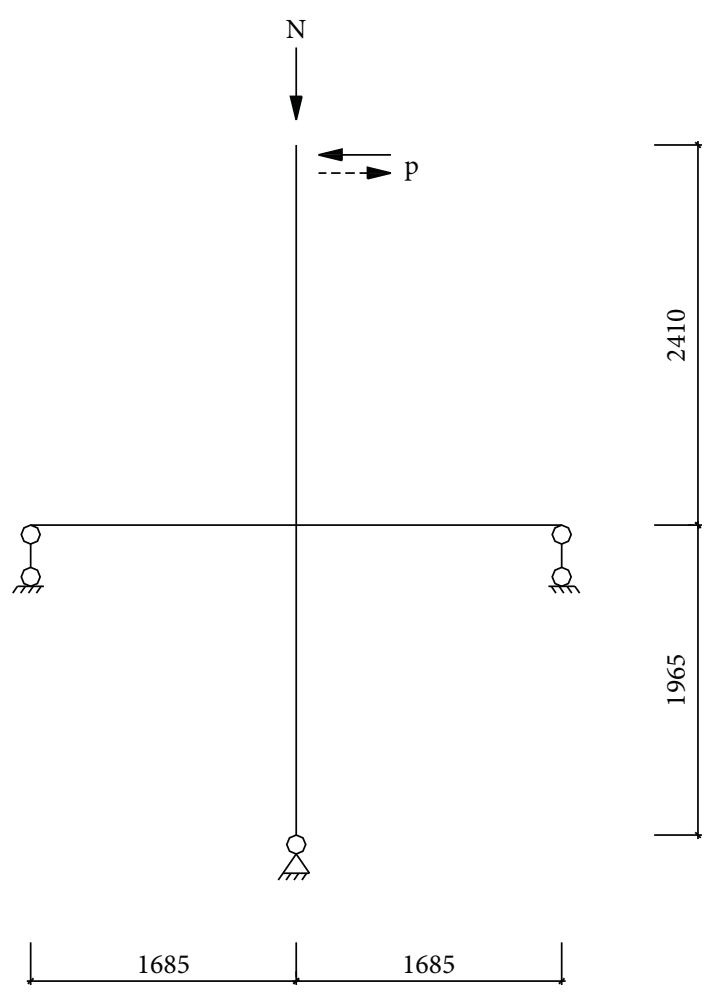

FIGURE 4: Loading schematic diagram.

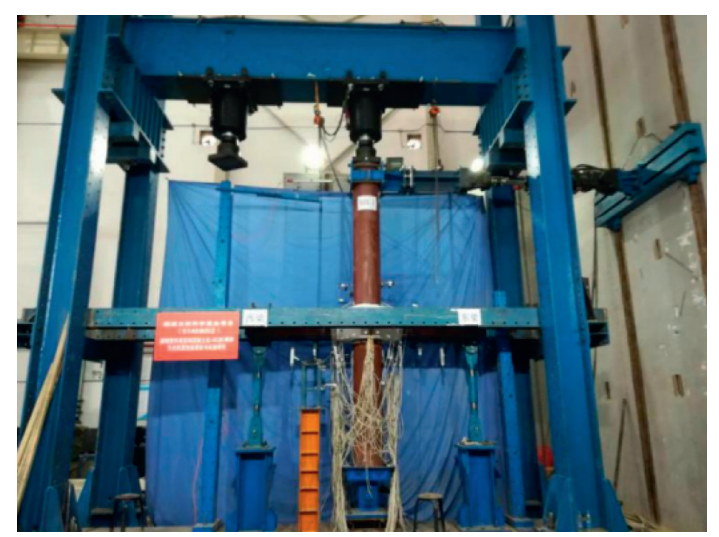

FIGURE 5: Loading panoramic photo.

beam on the west side of the SH-1 specimen is fractured when the SH-1 specimen is finally destroyed), and the concrete at the junction of the ring beam and the steel beam cracks and partially falls off. In the whole test process, except for the beam end, there is no obvious failure sign in the joint core area of the two specimens. Figures 7 and 8 show the final failure state of $\mathrm{SH}-1$ and $\mathrm{SH}-2$ specimens.

On account of the difference in the volume reinforcement ratio of the ring beam between the two specimens, the concrete shedding degree of the ring beam is quite different when the two specimens are damaged. Due to the high reinforcement ratio of $\mathrm{SH}-1$ specimen, especially the stirrups are arranged near the two sides of the steel beam at the junction of the steel beam and the ring beam, and the concrete of the ring beam of the specimen will not fall off a lot after being broken, but it is still connected to the damaged ring beam. Due to the small stirrup ratio of the SH-2 specimen, the stirrups on both sides of the junction between the steel beam and the ring beam are far away from the steel beam, resulting in a large amount of concrete falling off near the steel beam after fragmentation.

3.2. Load-Displacement Hysteretic Curve at the Top of the Column. The load-displacement hysteretic curves of the two specimens are shown in Figure 9. It can be seen from the hysteretic curves of the above two specimens that, at the initial stage of cyclic loading, the hysteretic curves are parallelogram. With the continuous cyclic loading, the hysteretic curves gradually change from parallelogram to rectangle. At the same time, the fullness of the hysteretic curves of the two specimens is much higher than that of the corresponding steel frame joints and concrete frame joints, showing a very good energy dissipation performance.

At the same time, the curves of the two specimens show different characteristics: first, due to the poor manufacturing quality of specimen $\mathrm{SH}-1$, when loading to the second cycle of $180 \mathrm{~mm}$, the west side of the weld is completely broken, resulting in a sharp drop in the curve. Second, the hysteretic curve of the specimen $\mathrm{SH}-1$ has a more obvious difference about the horizontal coordinate axis; the results show that the peak value of the positive horizontal force (thrust) at the top of the column is significantly greater than the negative horizontal force (tension) at the top of the column under each displacement amplitude loading cycle.

3.3. Skeleton Curve. The skeleton curve can be obtained by connecting the peak points of each loading point in the same direction on the load-displacement hysteretic curve. The skeleton curve cannot only reflect the load and displacement of each characteristic point in the loading process but also 


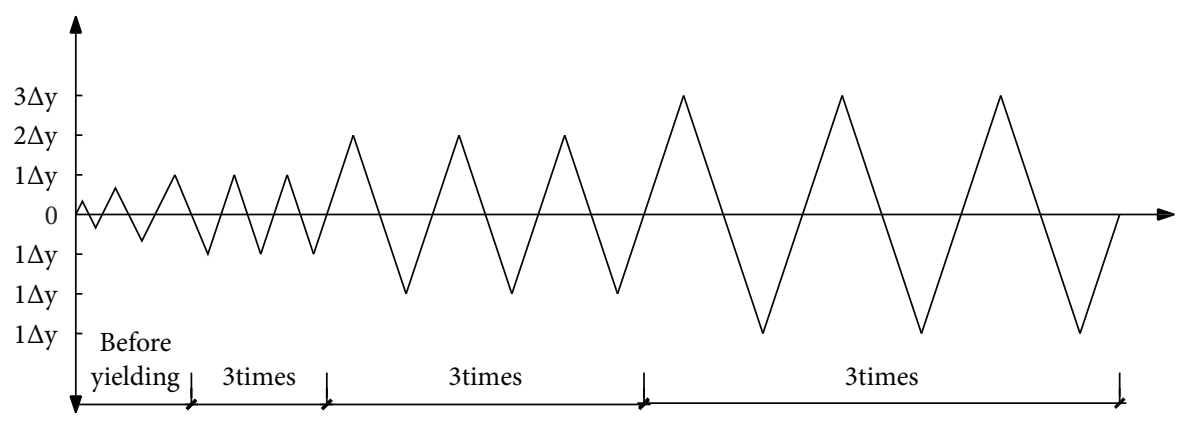

FIGURE 6: Loading system of the test.

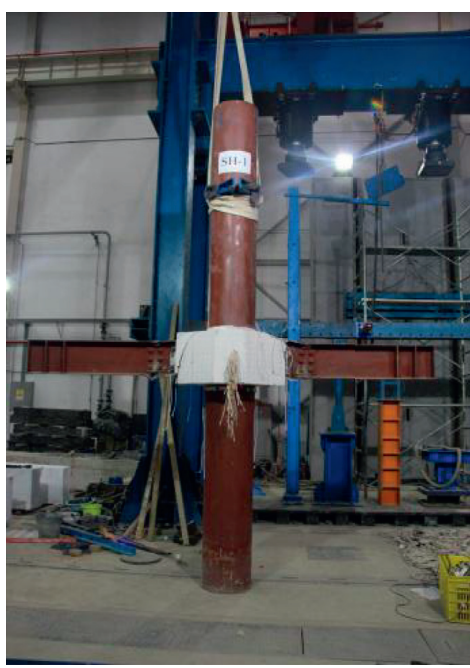

(a)
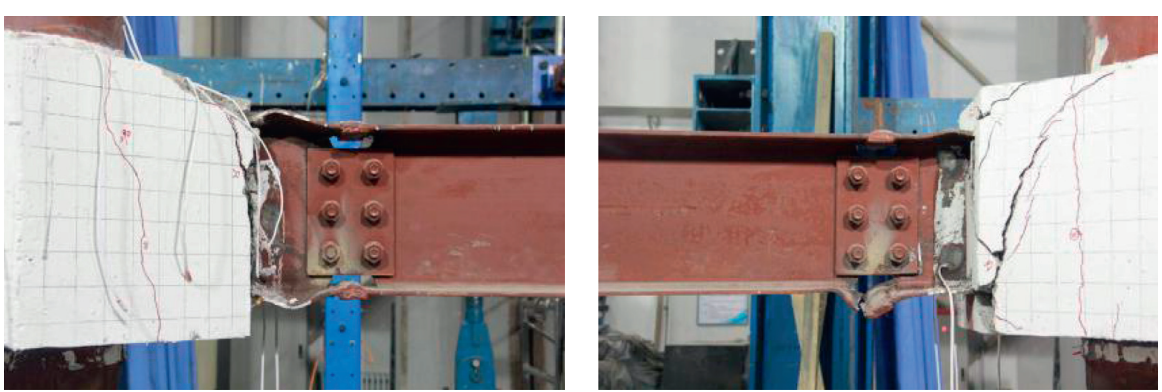

(b) (c)

Figure 7: Failure of the specimen (SH-1). (a) Overall situation after failure. (b) Failure of the east steel beam and ring beam. (c) Failure of the west steel beam and ring beam.

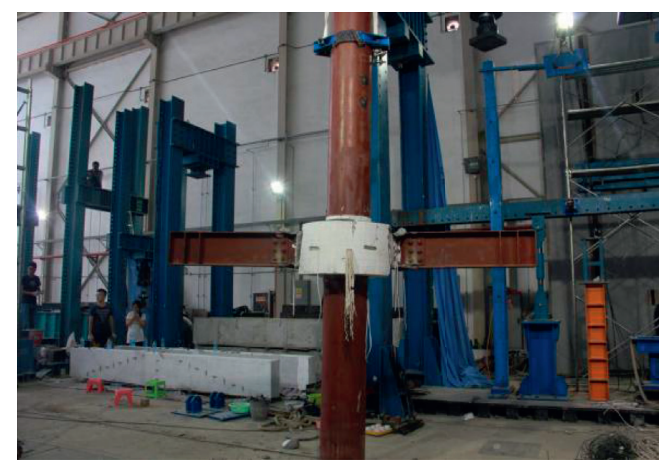

(a)

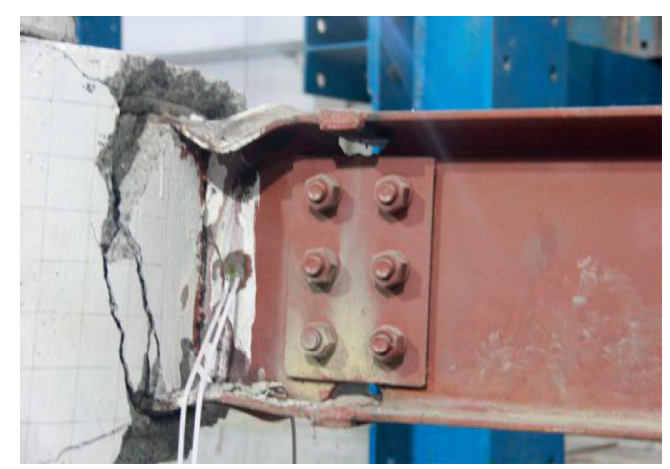

(b)

Figure 8: Failure of the specimen ( $\mathrm{SH}-2$ ). (a) Overall situation after failure. (b) Failure of the east steel beam and ring beam.

reflect the energy absorption, ductility, strength, stiffness, and degradation of the structure or component under repeated loading. Figure 10 shows the skeleton curve of each specimen.

From the skeleton curves of each specimen, it can be seen that the skeleton curves of the two specimens show obvious S-shape, and they have experienced three stages of elasticity, elastoplasticity, and failure. During the loading process, the positive and negative directions of the specimens are not completely symmetrical; especially, the $\mathrm{SH}-1$ specimen is obvious; the influence of ring beam shape and ring beam reinforcement ratio on the bearing capacity and deformation capacity of the joint is not significant; the two specimens are not symmetrical. After the specimens enter the plastic state, with the continuous increase of the displacement at the top of the column, the load does not immediately decrease, indicating that both specimens have good ductility; the 


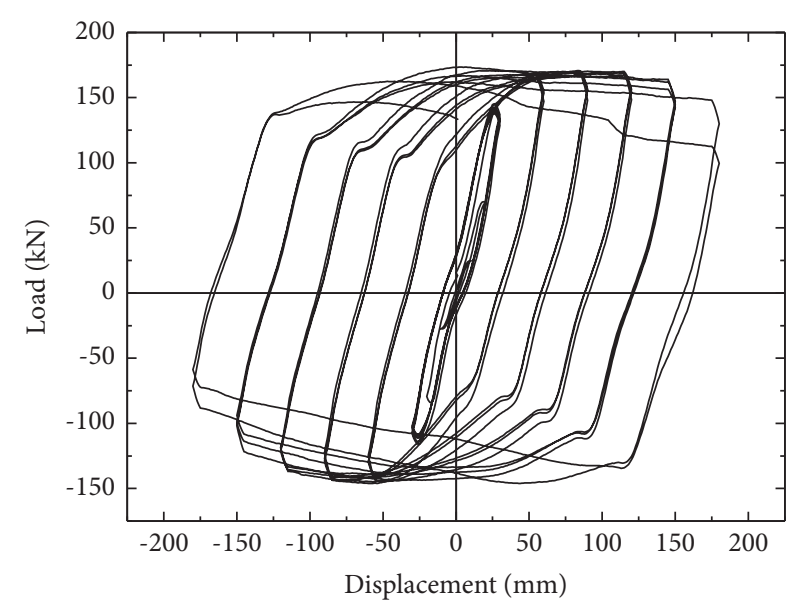

(a)

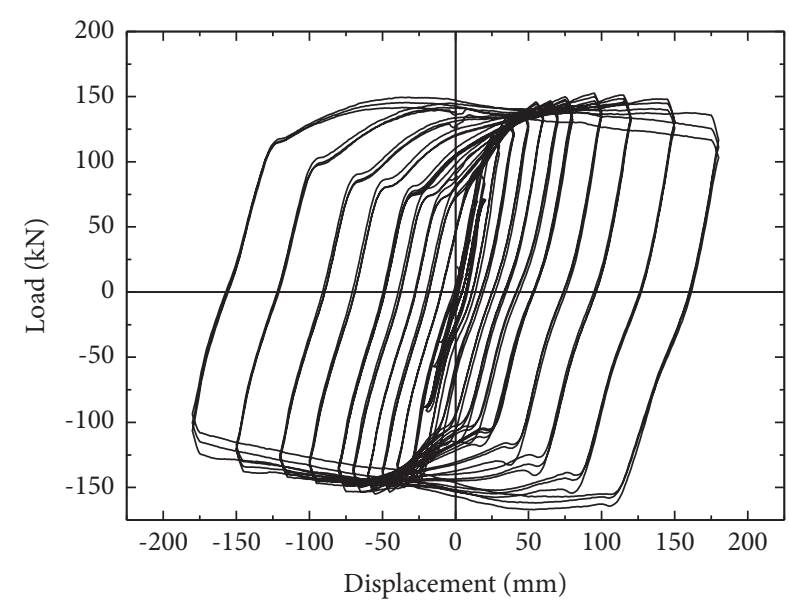

(b)

FIgURE 9: Load-displacement hysteretic curve of specimen column top. (a) $\mathrm{SH}-1$. (b) $\mathrm{SH}-2$.

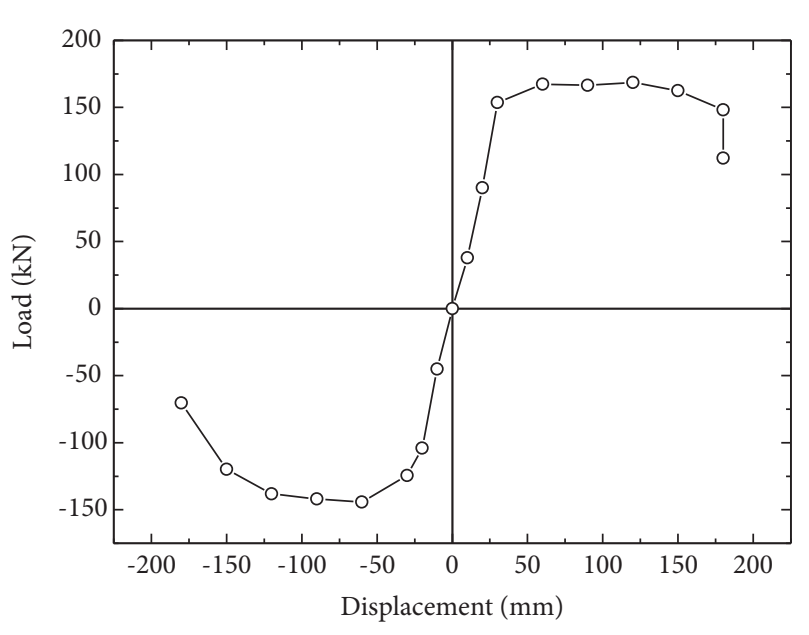

(a)

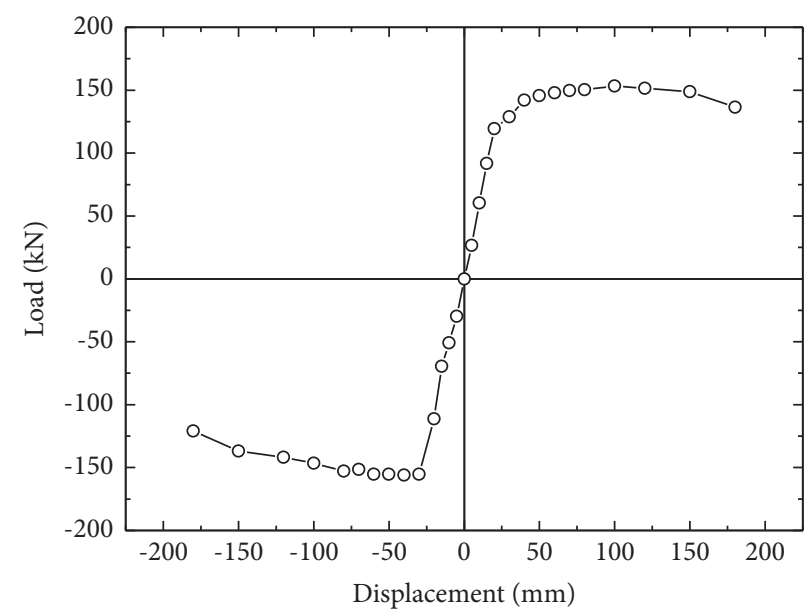

(b)

FiguRE 10: Load-displacement skeleton curve of the specimen column top. (a) SH-1. (b) SH-2.

skeleton curves of both specimens have no obvious yield point; and after the peak load, the curve and the stiffness gradually decrease.

3.4. Characteristic Point Load and Ductility Index of Specimens. It can be seen from the skeleton curve of the two specimens that there is no obvious yield point on the skeleton curve. Therefore, this paper adopts the "general yield moment method" to determine the displacement and load value of the characteristic points (yield, ultimate, and failure) in the loading process of the two specimens. The determination method is shown in Figure 11. $P_{y}, \Delta_{y}, P_{\max }$, $\Delta_{\max }, P_{u}$, and $\Delta_{u}$ determined by the above method are shown in Table 3.

It can be seen from the above table, skeleton curve, and hysteretic curve that the positive and reverse force performance of specimen $\mathrm{SH}-1$ is quite different. However, this situation does not appear in the test of specimen SH-2, which may be caused by the deviation of the east and west steel beams of $\mathrm{SH}-1$ in the process of processing and test installation.

The displacement ductility coefficient $(\mu)$ [28] is an index reflecting the plastic deformation capacity of the structure under earthquake action. The larger the displacement ductility coefficient is, the better the ductility of the structure or component is. The calculation of the displacement ductility coefficient is shown in

$$
\mu=\frac{\Delta_{u}}{\Delta_{y}}
$$

where " $\Delta_{u}$ " is the horizontal displacement at the top of the column when the joint specimen fails and " $\Delta_{y}$ " is the horizontal displacement at the top of the column when the joint specimen yields. The calculation is shown in Table 3.

The interlaminar deformation angle $(\varphi)$ of each joint specimen can be obtained according to the geometric relationship. The calculation of ductility coefficient of interlaminar deformation angle is shown in 


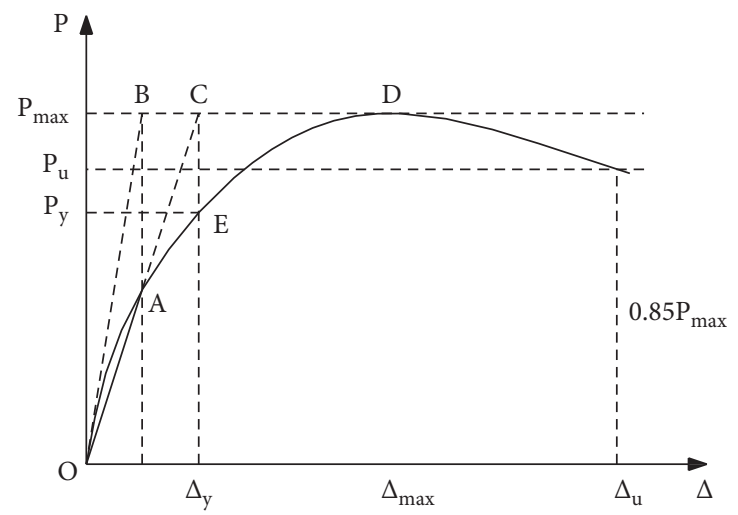

Figure 11: Determination method of the characteristic point load.

TABle 3: Load and displacement of the characteristic point.

\begin{tabular}{llcccccc}
\hline \multirow{2}{*}{ Specimen } & & \multicolumn{2}{c}{ Yield state } & \multicolumn{2}{c}{ Ultimate load state } & \multicolumn{2}{c}{ Failure state } \\
& & $P_{y}(\mathrm{kN})$ & $\Delta_{y}(\mathrm{~mm})$ & $P_{\max }(\mathrm{kN})$ & $\Delta_{\max }(\mathrm{mm})$ & $P_{u}(\mathrm{kN})$ & $\Delta_{u}(\mathrm{~mm})$ \\
\hline \multirow{2}{*}{ SH-1 } & Positive & 155.80 & 41.67 & 168.44 & 60.01 & 143.17 & 178.51 \\
& Reverse & 127.65 & 32.35 & 144.29 & 60.04 & 122.65 \\
\hline \multirow{2}{*}{ SH-2 } & Positive & 131.25 & 31.25 & 151.46 & 80.01 & 128.74 \\
& Reverse & 120.74 & 30.29 & 155.31 & 60.03 & 180.02 \\
\hline
\end{tabular}

$$
\mu_{\varphi}=\frac{\varphi_{u}}{\varphi_{y}}
$$

where " $\varphi_{u}$ " is the interlaminar deformation angle when the joint specimen fails and " $\varphi_{y}$ " is the interlaminar deformation angle when the joint specimen yields. The calculation is shown in Table 4.

It can be seen from Table 3 and the skeleton curves of the two specimens that the maximum displacement ductility coefficient and interlaminar deformation angle ductility coefficient of the two specimens are 5.76 and the minimum is 4.28. The results show that the interlaminar deformation angle ranges from 0.00658 to 0.00905 at yield and from 0.0335 to 0.0391 at failure. The relevant index is far more than the general reinforced concrete structure, which has very good ductility and deformation performance.

3.5. Strain Analysis of the Specimen. According to the failure characteristics of the specimen in Section 3.1, the ultimate failure of the two specimens occurs at the junction of the steel beam and the ring beam, where the plastic hinge is formed in the whole section of the steel beam, and the concrete cracks and falls off. The following takes the SH-1 specimen as an example to illustrate the characteristics of the data of each strain measurement point of the specimen.

From the load-strain hysteretic curves of flange, web, and ring beam concrete at the junction of steel beam and ring beam, it can be seen that the flange at the junction of steel beam and ring beam first enters into yield state and then slightly warps compared with the web. When the final specimen fails, plastic hinge is formed at the junction of the east and west steel beams and the ring beam. During the whole loading process, the maximum strain of each measuring point of flange reaches $40000 \mu \varepsilon$ (as shown in Figure $12(\mathrm{a})$ ). The web in yield state lags behind the flange (as shown in Figure 12(b)). At the initial stage of loading, the ring beam concrete is not cracked, the load-strain curve is linear, and there is almost no residual strain. However, with the cracking of the concrete, the strain value of each measuring point increases rapidly, and most of the deformation cannot be recovered, which indicates that, after the crack appears, with the continuous loading, the crack can hardly be closed, and the residual deformation is very large (as shown in Figure 12(c)).

From the reading of strain measuring points arranged in the rest parts of the specimen, it can be seen that the strain values of the rest parts remain elastic throughout the loading process, except that the central part of the section steel web in the column enters the yield state in the later stage of loading, which fully indicates that the existence of concrete ring beam makes the failure part move out, which plays a good role in protecting the core area of the joint.

3.6. Energy Dissipation Performance of Specimens. Energy dissipation performance is another important index to investigate the seismic performance of a certain structure. The equivalent viscous damping coefficient $\left(h_{e}\right)$ is often used to judge the energy dissipation capacity of the structure, and " $h{ }_{e}$ " is calculated according to the envelope diagram of the load-displacement hysteretic curve of the specimen (as shown in Figure 13). According to formula (3), the equivalent viscous damping coefficients of the hysteresis loops of the two specimens under each displacement amplitude are calculated, and the curves are drawn as shown in Figure 14: 
TABle 4: Ductility index of specimens.

\begin{tabular}{|c|c|c|c|c|c|}
\hline \multicolumn{2}{|c|}{ Specimen } & \multirow[t]{2}{*}{ Displacement ductility coefficient } & \multicolumn{3}{|c|}{$\begin{array}{c}\text { Interlaminar deformation angle and ductility } \\
\text { coefficient }\end{array}$} \\
\hline & & & $\varphi_{y}(\mathrm{rad})$ & $\varphi_{u}(\mathrm{rad})$ & $\mu_{\varphi}=\varphi_{u} / \varphi_{y}$ \\
\hline \multirow{2}{*}{ SH-1 } & Positive & 4.28 & 0.00905 & 0.0388 & 4.29 \\
\hline & Reverse & 4.77 & 0.00703 & 0.0335 & 4.77 \\
\hline \multirow{2}{*}{$\mathrm{SH}-2$} & Positive & 5.76 & 0.00679 & 0.0391 & 5.76 \\
\hline & Reverse & 5.20 & 0.00658 & 0.0342 & 5.20 \\
\hline
\end{tabular}

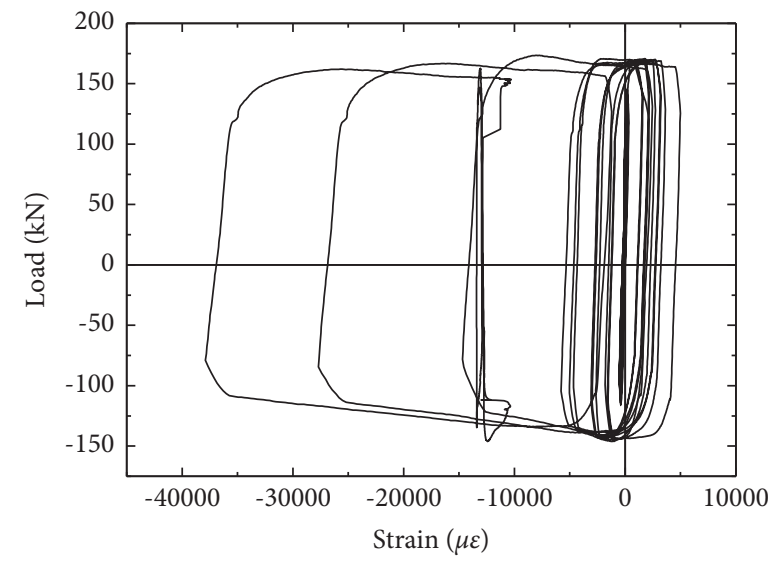

(a)

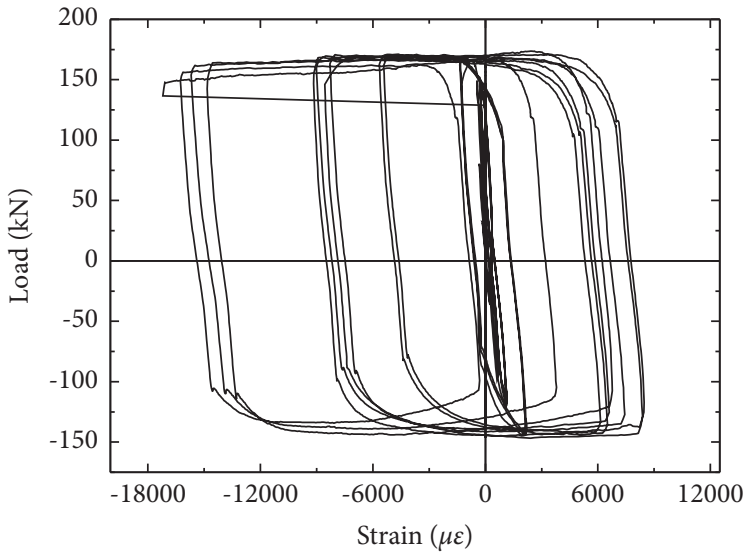

(b)

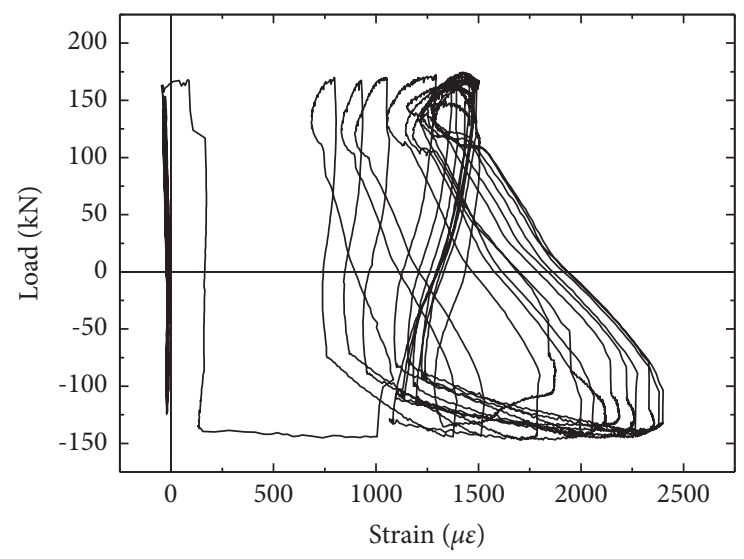

(c)

Figure 12: Load-strain hysteretic curves. (a) Flange. (b) Web. (c) Ring beam concrete.

$$
h_{e}=\frac{1}{2 \pi} \frac{\text { area of hysteresis curve }(\mathrm{FBE}+\mathrm{FDE})}{\text { area of triangle }(\mathrm{AOB}+\mathrm{COD})} .
$$

From the equivalent viscous damping coefficient curves of the above two specimens, the following conclusions can be obtained:

(1) The ultimate equivalent viscous damping coefficients $\left(h_{e}\right)$ of the two specimens are 0.535 (SH-1) and 0.615 (SH-2). Relevant studies have shown that the " $h_{e}$ " of reinforced concrete joints is 0.1 and that of steelreinforced concrete joints is about 0.3 . " $h_{e}$ ” values of the two new joints are 5.35 times and 6.15 times of reinforced concrete joints and 1.78 times and 2.05 times of steel-reinforced concrete joints. The joint specimen has superior energy dissipation performance.

(2) In the initial elastic stage, the equivalent viscous damping coefficients of the two specimens are relatively small, and the energy dissipation capacity increases rapidly with the increase of cyclic loading displacement; after entering the yield stage, the plastic hinge is formed at the end of the steel beam, and the concrete at the junction of the steel beam and the ring beam cracks and gradually falls off, but the energy dissipation capacity of the two specimens continues to improve. With the continuous loading, the beam end is completely cut off. The bearing capacity of the two specimens remains at a high level, 


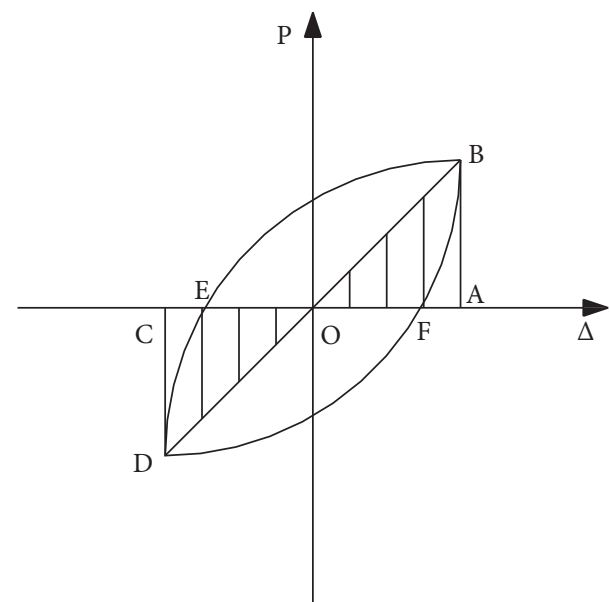

FIgURE 13: Envelope diagram.

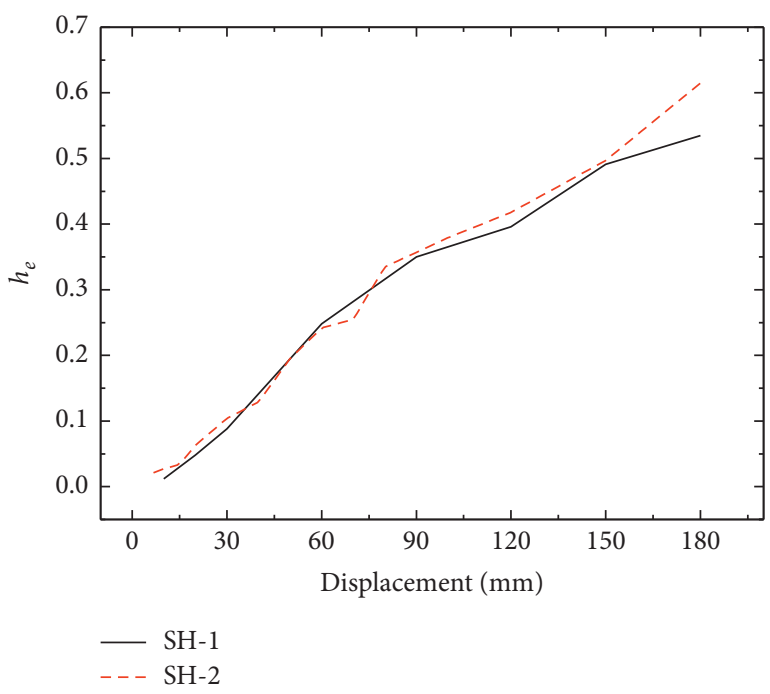

FIgURE 14: Equivalent viscous damping coefficient curve.

and the energy dissipation capacity is still in a rising state until the end of the failure loading. It fully shows that the energy dissipation capacity of the two specimens increases with the continuous low-cycle cyclic loading.

(3) From the initial stage of loading to the near failure of the specimen, the energy dissipation index curves of the two joint specimens have little difference, showing the phenomenon of alternating rise, while the end of the curve shows bifurcation. This is due to the sharp drop of the hysteretic curve caused by the fracture of the lower flange weld of the steel beam on the west side of the specimen SH-1, which makes the energy dissipation indexes of the final specimen $\mathrm{SH}$ 1 smaller than that of $\mathrm{SH}-2$.

3.7. Strength Degradation of Specimens. Strength degradation refers to the characteristic that the bearing capacity of the specimen decreases with the increase of the number of reciprocating loading processes under the condition of constant displacement amplitude. The strength degradation of joint specimens under repeated loading has an important impact on its seismic performance. In this paper, the same level bearing capacity reduction coefficient $\left(\lambda_{i}\right)$ and the overall bearing capacity reduction coefficient $\left(\lambda_{j}\right)$ are used to reflect the strength degradation characteristics of joint specimens in the test.

The same level bearing capacity reduction coefficient is as follows:

$$
\lambda_{i}=\frac{P_{j}^{i} \min }{P_{j}^{1} \max },
$$

where $P_{j}^{i}$ min is the minimum value of the peak load in the same loading cycle when the displacement is $j$ and $P_{j}^{1} \max$ is the peak point load of the first loading cycle when the displacement is $j$.

The overall bearing capacity reduction coefficient is as follows:

$$
\lambda_{j}=\frac{P_{j}}{P_{\max }},
$$

where $P_{j}$ is the minimum value of the load at the peak point of the $j$-th loading cycle and $P_{\max }$ is the ultimate value of the bearing capacity of the specimen during the whole loading process.

According to the above calculation method, the bearing capacity reduction coefficient of $\mathrm{SH}-1$ and $\mathrm{SH}-2$ under different displacement loads can be obtained in the process of positive (push) and reverse (pull) loading, and the bearing capacity reduction coefficient curve of SH-1 and $\mathrm{SH}-2$ is drawn, as shown in Figure 15.

The following conclusions can be drawn from the bearing capacity reduction coefficient curves of the above two specimens:

(1) At the initial stage of loading, with the increase of displacement amplitude, the values of $\lambda_{i}$ and $\lambda_{j}$ of the two specimens increase rapidly. With the continuous loading, the two values remain stable and fluctuate in a certain range. With further increase of displacement amplitude, the values of $\lambda_{i}$ and $\lambda_{j}$ decrease slowly, and the decrease is obvious until the last displacement.

(2) From the initial stage of loading to the near failure of the specimen, the $\lambda_{i}$ values of the two specimens are kept at a high level (except for the corresponding value of $\lambda_{i}$ of SH-2 specimen when the displacement is $20 \mathrm{~mm}$ in the positive direction), and the fluctuation range is between 0.933 and 0.977; this shows that both specimens have strong resistance to strength degradation. When the loading reaches $180 \mathrm{~mm}$ displacement amplitude, the $\lambda_{i}$ value of the two specimens decreases obviously. The curve of the $\mathrm{SH}-1$ specimen decreases more than that of the SH-2 specimen, because the lower flange of the west steel beam breaks during the second $180 \mathrm{~mm}$ cycle of the $\mathrm{SH}-1$ specimen, 


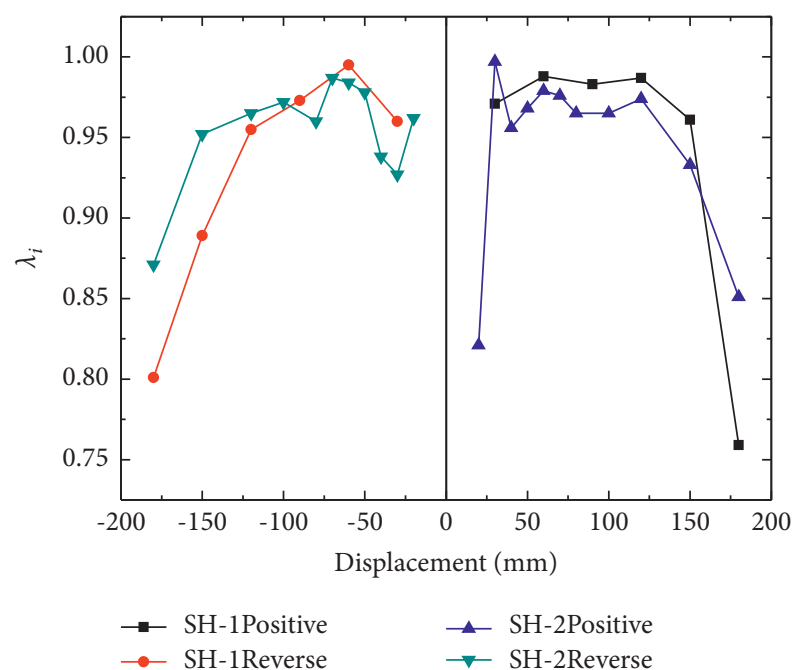

(a)

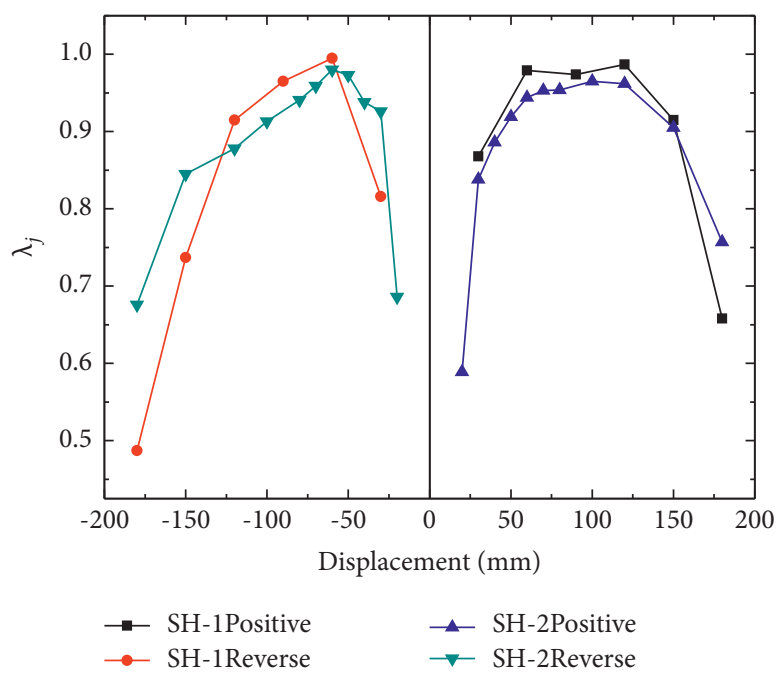

(b)

FIGURE 15: Bearing capacity reduction coefficient curve. (a) The same level bearing capacity reduction coefficient curve. (b) Overall bearing capacity reduction coefficient curve.

resulting in a sharp drop in load, which leads to a larger drop in $\lambda_{i}$ value. Comparing Figures 15(a) with 15(b), it can be seen that the same level strength degradation law of the two specimens is similar to the overall strength degradation law. Although the strength degradation curve values of the two specimens are different, the trend of the curve is basically the same, which also shows that the strength degradation performance of the specimens mainly depends on the performance of the steel beam end rather than the ring beam reinforcement.

3.8. Stiffness Degradation of Specimens. Stiffness degradation is a characteristic that the stiffness of specimen decreases with the increase of repeated loading times under the condition of constant displacement amplitude, which is mainly caused by steel yield and concrete cracking and falling off. The stiffness degradation is represented by loop stiffness [28].

The loop stiffness is as follows:

$$
K_{i}=\frac{\sum_{i=1}^{n} P_{j}^{i}}{\sum_{i=1}^{n} \Delta_{j}^{i}}
$$

where $K_{i}$ is the loop stiffness, $P_{j}^{i}$ is the peak point load value of the $i$-th cycle when the displacement is $j, \Delta_{j}^{i}$ is the peak point deformation value of the $i$-th cycle when the displacement is $j$, and $n$ is the number of cycles under the same displacement.

From the above calculation method, the loop stiffness of the two joint specimens at all levels of displacement can be obtained, and the stiffness degradation curve of the two joint specimens is drawn, as shown in Figure 16.

The following conclusions can be drawn from the stiffness degradation curves of two specimens:

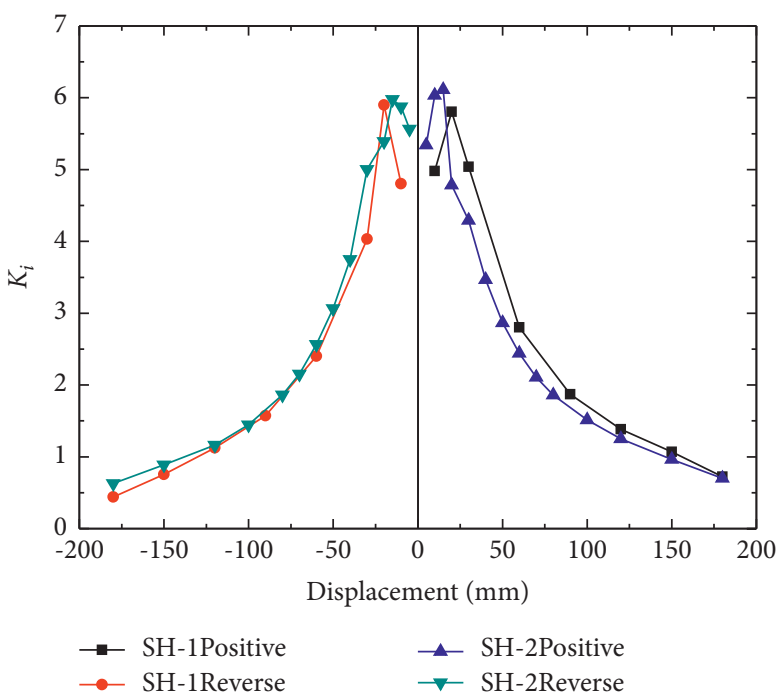

Figure 16: Stiffness degradation curve.

(1) In the initial stage of loading, the loop stiffness value of the two specimens increases slightly. When the two specimens reach their yield displacement and enter the cyclic loading stage, the $K_{i}$ value reaches the maximum and then decreases with the continuous loading. In the middle and late stages of loading, the reduction rate of $K_{i}$ value gradually decreases, which is reflected in the gradual decrease of the slope of the stiffness degradation curve and the gradual slowing of the curve. This shows that the ability to resist stiffness degradation is superior.

(2) In the early stage of loading, the $K_{i}$ value of $\mathrm{SH}-2$ is slightly higher than that of SH-1. In the middle and late stage of loading and until failure, the positive stiffness degradation curve of $\mathrm{SH}-1$ is always higher than that of SH-2; that is, the $K_{i}$ value of SH-1 is 
greater than that of SH-2 at the same positive displacement, while the negative stiffness degradation curve of SH-1 and $\mathrm{SH}-2$ has little difference in the process of test loading. From the test results, it can be seen that there is a great difference between the positive and reverse mechanical properties of $\mathrm{SH}-1$ specimen during the loading process, and the difference between the positive and reverse load values of the three characteristic points is $16.73 \%-22.05 \%$, which leads to the fact that the value of the negative stiffness degradation curve is smaller than that of the positive.

3.9. Deformation Analysis of the Joint Area. The joint area refers to the joint area of beam and column. Under the action of beam end reaction and column end horizontal thrust, the joints will expand, bend, and shear. Due to the steel beam constraints, the expansion and bending deformation of the joint region can be ignored. This paper focuses on the shear deformation of the joint region.

Due to the existence of a concrete ring beam, it is not convenient to arrange dial indicator in the diagonal direction outside the joint area for measurement. Therefore, the method in [29] is adopted in this test, and strain gauges are pasted in the core area of the joint to measure the deformation of the steel web along the diagonal direction in the core area of the joint during loading (as shown in Figure 17). In order to compare the data of different specimens when analyzing the data, the data measured by the strain gauge when the axial pressure of the specimen has been applied and the horizontal load on the top of the column has not been applied is taken as the datum point data (zero points), the difference between the real strain test data and the datum point when the horizontal displacement on the top of the column is the maximum is taken as the standard strain data, and then the average value of two diagonal strains is taken, respectively. It should be noted that, in the process of specimen test on SH-2, due to the limitation of acquisition instrument, when the load is applied to $80 \mathrm{~mm}$ cycle, the data acquisition of all strain measuring points stops, so the strain data of node domain of $\mathrm{SH}-2$ specimen is only collected at $80 \mathrm{~mm}$ cycle.

It can be seen from Table 5 that the strain measuring points of nos. 13, 14, 15, 16, and 17 steel are compressive strain at the maximum horizontal displacement at the top of the column, and the strain measuring points of nos. 18, 19, and 20 steel are tensile strain at the maximum horizontal displacement at the top of the column; that is, one diagonal of the joint area is compressive deformation and the other diagonal is tensile deformation. Moreover, when the horizontal displacement of the top of the column reaches the maximum, the average strain does not reach the yield strain of the steel and remains in the elastic state.

Using the average value of the maximum strain in the diagonal direction of the node area in Table 5 and using the geometric relationship shown in Figure 18 and formulas (7) and (8), the actual deformation value and relevant parameters in the diagonal direction of the node core area can be calculated by Hooke's law, as shown in Table 6.

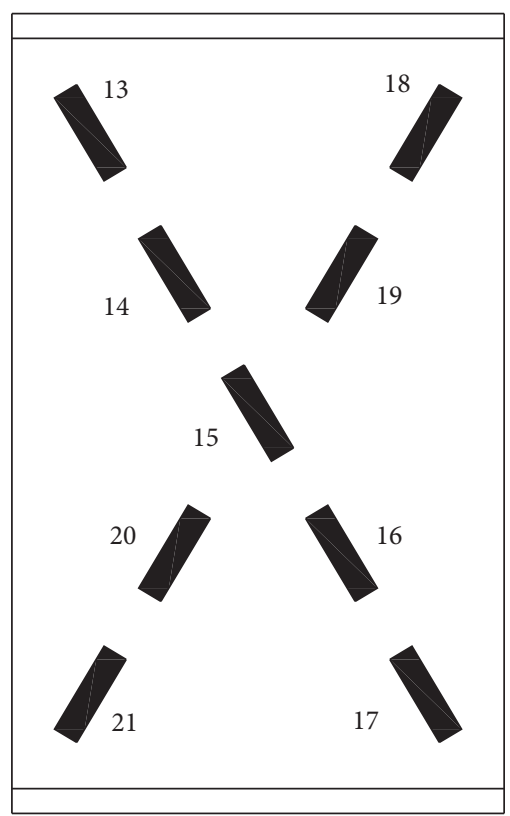

FIgURE 17: Strain gauges in the joint area. follows:

The average deformation in a diagonal direction is as

$$
\bar{X}=\frac{\left|\Delta_{1}+\Delta_{2}\right|+\left|\Delta_{3}+\Delta_{4}\right|}{2} .
$$

Because $\sin \theta=b / \sqrt{a^{2}+b^{2}}, \cos \theta=a / \sqrt{a^{2}+b^{2}}, \alpha_{1}=\bar{X}$ $\sin \theta / a$, and $\alpha_{2}=\bar{X} \cos \theta / b$. The shear angle is

$$
\gamma=\alpha_{1}+\alpha_{2}=\frac{\sqrt{a^{2}+b^{2}}}{a b} \bar{X} .
$$

It can be seen from Table 6 that when the horizontal displacement of the top of the column reaches $180 \mathrm{~mm}$, the maximum shear angle deformation of the specimen $\mathrm{SH}-1$ is $9.85 \%$ of the relative ultimate angle of the beam column. When the horizontal displacement of the top of the column reaches $80 \mathrm{~mm}$ and the specimen is adjacent to the failure, the maximum shear angle deformation of the specimen $\mathrm{SH}$ 2 is only $5.58 \%$ of the relative ultimate angle of the beamcolumn. It can be seen that the shear strength and stiffness of the joint region of this kind of joint specimen are very large, which meets the requirements of "strong joints and weak members" of the structure, and the shear deformation of the joint region has a negligible effect on the deformation of the structure.

\section{Preliminary Design Recommendation}

4.1. Structural Design Recommendation. It can be seen from Section 3 that the new joint proposed in this paper has excellent seismic performance. Therefore, on the basis of meeting the requirements of seismic and bearing capacity, it is necessary to strive for simple structure and convenient construction. Combined with some current codes and research results, the following structural design suggestions are put forward for this kind of joint: 
TABLE 5: Strain standard data of joint area.

\begin{tabular}{lccccccccccc}
\hline \multirow{2}{*}{ Specimen } & & \multicolumn{9}{c}{ Steel strain gauge number and strain measurement value $(\mu \varepsilon)$} \\
& 13 & 14 & 15 & 16 & 17 & Average & 18 & 19 & 20 & 21 & Average \\
\hline SH-1 & -2658 & Invalid & -421 & Invalid & -41 & -1040 & Invalid & Invalid & 320 & 489 & 405 \\
SH-2 & -326 & -573 & -308 & -100 & -1164 & -494 & 51 & 757 & 1045 & Invalid & 618 \\
\hline
\end{tabular}

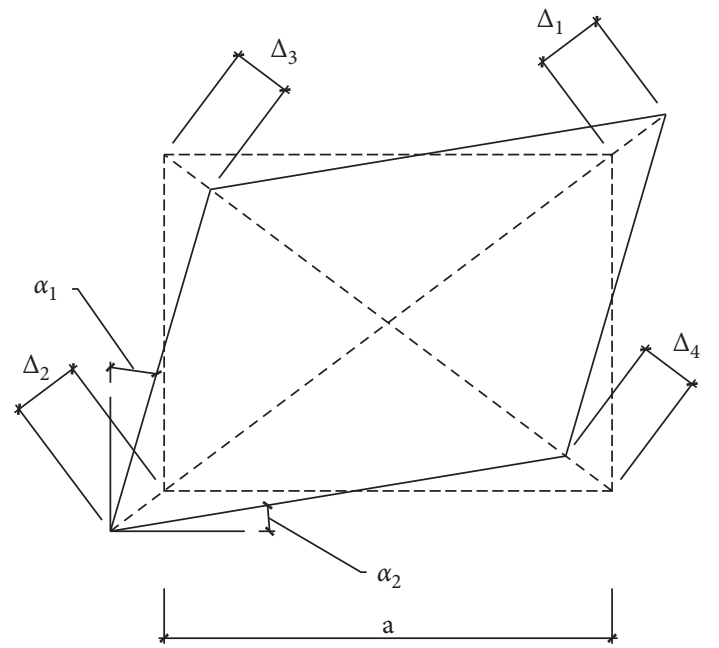

Figure 18: Geometric relationship of shear deformation.

TABLE 6: Shear deformation in the joint area.

\begin{tabular}{lcccc}
\hline Specimen & $\bar{X}(\mathrm{~mm})$ & $\gamma$ & $\theta$ & $\gamma / \theta$ \\
\hline SH-1 & 0.2319 & $1.724^{\circ}$ & $17.5^{\circ}$ & 0.0985 \\
SH-2 & 0.1785 & $1.327^{\circ}$ & $23.8^{\circ}$ & 0.0558 \\
\hline
\end{tabular}

(1) In order to ensure that the circular steel tube does not bear the longitudinal load, the circular steel tube is disconnected in the joint area, and a $15 \mathrm{~mm}$ ring opening is reserved from the upper and lower edges of the concrete ring beam. At the same time, a reinforcing steel ring can be welded at the end of the steel pipe to prevent the tearing of the steel pipe weld caused by concrete expansion. The thickness of the reinforcing ring shall not be less than the wall thickness of the steel pipe, and the height shall not be less than 6 times the thickness of the steel pipe.

(2) When the shear bearing capacity of the core area of the joint is insufficient, the steel plate can be used to reinforce the section steel web in the column in the joint area. The thickness and reinforcement range of the steel plate shall be implemented according to the relevant provisions in [30].

(3) In order to ensure the overall mechanical properties of the column, a certain number of shear studs shall be set on the section steel flange in the column outside the reinforcement skeleton in the joint area, and the specification and spacing of shear studs shall be implemented according to the relevant provisions in $[31,32]$.

(4) In order to avoid holes in the corner of the horizontal stiffener in the node area when pouring concrete, it is necessary to set an exhaust hole in this part, and the opening form shall be implemented according to the relevant provisions in [33].

(5) In the design of the joint, the number of main reinforcements in the column passing through the flange of the steel beam shall be minimized. When it is inevitable, appropriate reinforcement measures shall be taken. At the same time, when the column stirrup through hole is reserved on the web of the steel beam, the section loss rate of the web shall not exceed $25 \%$ [34].

4.2. Calculation Formula of Shear Capacity. Based on the experimental study of seismic performance of joints, the calculation formula of shear capacity of such joints is proposed [35]:

$$
\begin{aligned}
V & =V_{f}+V_{h}+V_{s v}+V_{h l}+V_{l f} \\
& =0.96 \phi_{j} \eta_{j} f_{t}\left(\mathrm{D}_{h l}-\mathrm{D}_{z}\right)\left[b_{0}+0.5\left(\mathrm{D}_{h l}+\mathrm{D}_{z}\right)\right]+\left(0.037 n_{0}+0.172\right) f_{c} b_{j} h_{j}+f_{y v} A_{s v} \frac{h_{0}-a}{s}+0.58\left(t_{w} h_{w} f_{y}+t_{l w} h_{l w} f_{l w}\right),
\end{aligned}
$$

where $V_{f}$ is the shear capacity of the section steel web in the column, $V_{h}$ is the shear capacity of the column concrete in the core area of the joint, $V_{s v}$ is the shear capacity of the stirrup in the joint area, $V_{H L}$ is the shear capacity of the concrete ring beam, and $V_{L F}$ is the shear capacity of the web of the cantilever short steel beam and the meaning of other symbols can be seen in [35]. 
It can be seen from the formula that the shear capacity of such joints consists of five parts. Compared with the results of the test and finite element numerical analysis [35], the formula is reasonable, which can provide a basis for the engineering design of such joints.

\section{Conclusion}

A new type joint of CTSRC column is designed. Through the pseudostatic test, the mechanical properties of this kind of new joints under earthquake action are investigated.

The main conclusions include the following:

(1) The failure modes of the two specimens are basically the same, and the existence of the concrete ring beam effectively protects the core area of the joint, which makes the failure move outward.

(2) The results show that the load-displacement hysteretic curves of the two specimens are very full, and the energy dissipation performance is excellent. The displacement ductility coefficient, interlayer deformation angle, and ductility coefficient of the two specimens are far greater than those of the traditional joints.

(3) The results show that the ultimate equivalent viscous damping coefficients $\left(h_{e}\right)$ of specimens are much larger than those of traditional joints. The specimens show strong resistance to strength degradation and stiffness degradation. The shear deformation in the joint area is very small and the stiffness is very large.

(4) The preliminary design recommendation is put forward, which can provide a basis for the engineering design of this new type of joint.

\section{Data Availability}

The data used to support the findings of this study are available from the corresponding author upon request.

\section{Conflicts of Interest}

The authors declare that there are no conflicts of interest with respect to the research, authorship, and/or publication of this paper.

\section{Acknowledgments}

This research was supported by the National Natural Science Foundation of China (no. 51408052), the Youth Science and Technology Star Project of Shaanxi Province (no. 2016KJXX51), Key Research and Development Plan of Shaanxi Province (no. 2018SF-354), and the Special Fund for Basic Scientific Research in Central Universities of Chang'an University (no. 300102289205).

\section{References}

[1] A. H. Varma, J. M. Ricles, R. Sause, and L.-W. Lu, "Seismic behavior and design of high-strength square concrete-filled steel tube beam columns," Journal of Structural Engineering, vol. 130, no. 2, pp. 169-179, 2004.

[2] A. Varma, J. Ricles, R. Sause, and L. Lu, "Seismic behavior of high-strength square CFT beam- columns," in Proceeding of 6th ASCCS Conference Los Angeles.confer.On Composit and Hybrid Structures, vol. 1, pp. 547-556, Los Angeles, Ca, USA, March 2002.

[3] A. Elremaily and A. Azizinamini, "Behavior and strength of circular concrete-filled tubu columns," Journal of Constructional Steel Research, vol. 58, no. 12, pp. 1567-1591, 2002.

[4] N. E. Shanmugam and B. Lakshmi, "State of the art report on steel-concrete composite columns," Journal of Constructional Steel Research, vol. 57, no. 10, pp. 1041-1080, 2001.

[5] X. Zhou, J. Liu, and S. Zhang, "Experimental study on seismic behavior of square steel tube confined steel reinforced concrete short columns," Journal of Building Structures, vol. 31, no. 7, pp. 49-55, 2010.

[6] J. Liu, X. Zhang, and S. Zhang, "Axial compression behavior of circular steel tube confined steel reinforced high strength concrete short columns," Journal of Building Structures, vol. 30, pp. 242-248, 2009.

[7] X. Zhou and J. Liu, "Seismic behavior and strength of tubed steel reinforced- concrete(SRC) short columns," Journal of Constructional Steel Research, vol. 66, no. 1, pp. 28-36, 2010.

[8] T. Yamamoto, J. Kawaguchi, and S. Morino, "Experimental study of scale effects on the compressive behavior of short concrete-filled steel tube Columns," in Proceedings of the Composite Construction in Steel and Concrete IV Proceedings of the Fourth International Conference on Composite Construction in Steel and Concrete, pp. 879-890, Slovakia, June 1994.

[9] A. Fam, F. Qie, and S. Rizkalla, "Conerete-filled steel tubes subjected to axial compression and later alcyclic loads," Journal of Struetural Engineering, vol. 130, no. 4, pp. 631-640, 2004.

[10] Q. Chen, J. Cai, and Y. Lin, "New concrete filled steel tubular(CFST) column-beam joint with discontinuous column tube(I)-Behavior at joint zone strengthened by horizontal mesh reinforcement under axial loading," Journal of South China University of Technology, vol. 30, no. 9, pp. 91-95, 2002.

[11] Q. Chen, J. Cai, Y. Lin, J. Liang, and Z. Tang, "New concrete filled steel tubular(CFST) column-beam joint with discontinuous column tube(II)-Behavior at joint zone strengthened by reinforcing ring bars under axial loading," Journal of South China University of Technology, vol. 30, no. 12, pp. 58-61, 2002.

[12] J. Liang, J. Cai, D. Yao, and Q. Chen, "Experimental research on a new type of concrete filled steel tubular column-beam joint:column tube discontinued in the joint zone," Journal of South China University of Technology, vol. 30, no. 10, pp. 79-83, 2002.

[13] J. Nie, Y. Bai, and C. Cai, "New connection system for confined concrete columns and beams I: experimental study," Journal of Structural Engineering, vol. 134, no. 12, pp. 17871799, 2008.

[14] Y. Bai, J. Nie, and C. Cai, "New connection system for confined concrete columns and beams. II: theoretical modeling," Journal of Structural Engineering, vol. 134, no. 12, pp. 1787-1799, 2008.

[15] L. Han, H. Qu, Z. Tao, and Z. Wang, "Experimental behaviour of thin-walled steel tube confined concrete column to RC beam joints under cyclic loading," Thin-Walled Structures, vol. 47, no. 8-9, pp. 847-857, 2009. 
[16] Y. F. Zhang, J. H. Zhao, and C. S. Cai, "Seismic behavior of ring beam joints between concrete-filled twin steel tubes columns and reinforced concrete beams," Engineering Structures, vol. 39, pp. 1-10, 2012.

[17] D. Gan, X. Zhou, B. Yan, F. Han, and J. Liu, "Experimental study on mechanical behavior of circular steel tube confined RC columns with ring stiffened joints," Journal of Building Structures, vol. 39, no. 4, pp. 91-101, 2018.

[18] D. Gan, X. Zhou, J. Liu, and B. Yan, "Calculation of shear capacity of steel tube confined reinforced concrete columns," Journal of Building structure, vol. 39, no. 9, pp. 96-103+111, 2018.

[19] W. Duan, J. Cai, X.-L. Tang, Q.-J. Chen, C Yang, and A. He, "Axial compressive behaviour of square through-beam joints between CFST columns and RC beams with multi-layers of steel meshes," Materials, vol. 13, no. 11, p. 2482, 2020.

[20] Y. Lin, K. Liu, T. Xiao, C. Zhou, and F. Lusquiños, "Shear bearing capacity of framework joints of steel-reinforced concrete-filled circular steel tube," Advances in Materials Science and Engineering, vol. 2020, Article ID 7324865, 15 pages, 2020.

[21] F. Yu, Y. C. Guan, Q. Q. Liu, S. L. Wang, and Y. Fang, "“Compressive behavior of joint core confined with core steel tube for connection of polyvinyl chloride-carbon fiber reinforced polymer -confined concrete column and reinforced concrete beam," Advances in Structural Engineering, vol. 23, no. 12, pp. 2570-2586, 2020.

[22] F. Yu, S. Bu, D. Li, C. Feng, and Y. Fang, "Experimental investigation and theoretical study on bearing capacity of strong PVC-FRP confifined concrete column-weak joint strengthened with core steel tube under axial loading," Construction and Building Materials, vol. 271, Article ID 121880, 2021.

[23] F. Yu, C. Feng, D. Li, and Y. Fang, "Finite element analysis on weak PVC-frp confined concrete column and strong joint strengthened with core CFST under axial compression," Iranian Journal of Science and Technology, Transactions of Civil Engineering, vol. 51, 2020.

[24] S. Peng, Z. Xiong, C. Xu, J. Fei, and X. Chen, "Research on shear strength of CFSST column and H-section with beam composite joint of unequal depth," Journal of Constructional Steel Research, vol. 180, Article ID 106575, 2021.

[25] China Construction Industry Press, Code For Seismic Test Methods of Buildings, China Construction Industry Press, Beijing, China, 2015.

[26] T. Zhou, Study on Seismic Behavior and Load-Carrying Capacity of Concrete-filled Square Tubular Column to Steel Beam Connection, Xi'an University of architecture and technology, Xi'an, China, 2004.

[27] C. Fang, Y. Ping, and Y. Chen, "Loading protocols for experimental seismic qualification of members in conventional and emerging steel frames," Earthquake Engineering and Structural Dynamics, vol. 49, no. 2, pp. 155-174, 2020.

[28] J. Fan, M. Tao, J. Nie, T. Li, and N. Zhao, "Experimental study on seismic behavior of steel reinforced concrete column steel truss composite joints," Journal of Building Structures, vol. 31, no. 2, pp. 1-10, 2010.

[29] J. Yuan, Analysis of Testing Method and Boundary Condition of Beam-To-Column Joint Behaviour in Frame, Shantou University, Shantou, China, 2004.

[30] China Construction Industry Press, Code For Design of Steel Structures, China Construction Industry Press, Beijing, China, 2017.
[31] Standards Press of China, Cheese Head Studs for Arc Stud Welding, Standards Press of China, Beijing, China, 2002.

[32] China Construction Industry Press, Technical Specification for Steel Structure of Tall Buildings, China Construction Industry Press, Beijing, China, 2015.

[33] China Construction Industry Press, Code For Design of Composite Structures, China Construction Industry Press, Beijing, China, 2016.

[34] China communication press, Beam To Column Frame Connections of Tall Building Composite Structures Analysis And Design, China communication press, Beijing, China, 2006.

[35] Y. Dai, S. Nie, and T. Zhou, "Shear capacity of circular steel tube confined H-SRC concrete column steel beam joint with ring beam," Journal of Jilin University (Engineering and Technology Edition), vol. 51, no. 3, pp. 977-988, 2021. 